\title{
Repeated Interactions and Contractual Detail: Identifying the Learning Effect
}

\author{
Bart S. Vanneste, Phanish Puranam \\ London Business School, University of London, London NW1 4SA, United Kingdom \\ \{bvanneste.phd2004@london.edu, ppuranam@london.edu\}
}

\begin{abstract}
$\mathrm{O}$ rganizations interacting repeatedly on similar transactions may learn from prior experiences, allowing contracts to be specified in greater detail. In this study, we analyze the conditions under which this learning effect is most likely to manifest itself. We do this by focusing on different parts of a contract as well as differences across transacting parties. Using a survey of information technology procurement contracts from 788 Dutch small- and medium-sized enterprises, we show that the learning effect is stronger for technical than for legal detail in contracts and is stronger for firms with information technology expertise than for firms without such expertise.
\end{abstract}

Key words: contractual detail; learning; repeated interactions; interorganizational relationships

History: Published online in Articles in Advance November 25, 2008.

\section{Introduction}

Complex contracting is an important mode of formal governance and arguably more prevalent than either spot markets or hierarchies (Powell 1987, Stinchcombe 1990, Hennart 1993). Yet, as is now widely recognized, formal contracts do not exist in a historical vacuum; they are often enmeshed within the context of an ongoing business relationship (Macaulay 1963, Macneil 1978, Granovetter 1985). Drawing on this insight, several management scholars have begun to study how contractual detail $^{1}$ - the extent to which relevant clauses are specified in contracts-depends on the history of contracting parties working together (Parkhe 1993, Luo 2002, Poppo and Zenger 2002, Mayer and Argyres 2004, Ryall and Sampson 2009). Apart from its theoretical significance, such research also has direct practical implications, as businesses could gain from a sharper understanding of how the nature and role of contract changes when they contract repeatedly with each other.

An important line of reasoning suggests that repeated interaction among contracting parties generates learning about how to specify the contract. For instance, Mayer and Argyres (2004) show that partners that interact repeatedly gradually learn more about the nature of the transaction they are engaging in and document this learning in their contracts. Contracting parties discover how the supplier's product interacts with the buyer's systems and processes. Each may also learn about specific ways in which the partner firm does business and effective ways for the two parties to collaborate. Because contracts may serve as a repository for this common knowledge, and because such knowledge accumulates through repeated interactions, a history of prior interactions may coexist with highly detailed contracts (Argyres et al. 2007).

Such learning effects can be important if we keep in mind that contracts serve not only as mechanisms for aligning incentives between parties, but also as a framework to coordinate their actions (Llewellyn 1931). Learning as enshrined in contracts is an important manifestation of the general phenomenon of learning to manage interfirm relationships effectively. As other scholars have demonstrated, such learning effects can have important strategic consequences for firms, as they can substantially improve the performance of their exchange relationships - and ultimately their own performance (Anand and Khanna 2000; Kale et al. 2000, 2002).

Our contribution in this paper is to analyze the conditions under which the learning effect is likely to be stronger or weaker by predicting differences in the marginal effects of prior interactions on contractual detail. In doing so, we focus sharply on the learning effect and avoid confounding with other consequences of relationship history. As the work of several scholars suggests, it is an empirical challenge to avoid confounding the learning effect with other consequences of prior interactions - such as trust. Organizational researchers have argued conceptually and shown empirically that interfirm trust increases with prior interactions (Anderson and Weitz 1989, Parkhe 1993). The consequences of this increased trust for contracts however remain unclear: although some scholars report a negative relationship between trust (or its proxies, such as prior interactions) and contractual/governance complexity (Crocker and Reynolds 1993, Parkhe 1993, Gulati 
1995, Corts and Singh 2004), others report a positive association (Zaheer and Venkatraman 1995, Luo 2002, Poppo and Zenger 2002, Ryall and Sampson 2009). It is not the purpose of the present study to decide between these arguments (see Puranam and Vanneste 2009 for a discussion). Rather, we note that regardless of whether trust formed through prior interactions encourages or discourages the use of detailed contracts, it makes the learning effect harder to identify-either by mimicking it or suppressing it, respectively. Put simply, it is difficult to test arguments about learning effects only by examining the relationship between prior interactions and contractual detail.

Instead, we adopt the widely followed strategy for eliminating alternative explanations in social science theory-to validate the existence of the learning effect, we rely on identifying sources of variation in the magnitude of the learning effect (Stinchcombe 1987). We argue that the learning effect is stronger for technical clauses than for legal clauses and for transactors with at least some in-house information technology (IT) expertise than for those with none. Under these conditions, we expect that a history of prior relationships can coexist with fairly detailed contracts, because of the learning effects that arise from that history. We test our arguments using data from a survey of IT procurement contracts entered into by 788 Dutch small- and mediumsized enterprises (SMEs). Our results broadly support our arguments.

\section{Theory}

\section{Learning and Repeated Contracting}

A contract is "an agreement which is legally enforceable or legally recognized as creating a duty" (Atiyah 1989 , p. 40). The precise role ascribed to contracts differs by theoretical lens. In agency theory, the use of contracts is twofold: incentive alignment and risk sharing (Eisenhardt 1989). In transaction cost economics, contracts are seen as offering (imperfect) protection against opportunistic behavior (Williamson 1975, 1985; Klein et al. 1978). Contractual clauses place penalties on noncooperative behavior, making such behavior less likely, or at least offering compensation in the event of such behavior. Property rights theorists view contracts as spelling out specific rights to ensure that the nonowner uses the asset in such a way that the interests of the owner are not harmed (Grossman and Hart 1986, Hart and Moore 1990).

In all these economic theories, the main purpose of contractual clauses is to mitigate inefficiencies created by incentive conflict. However, a contract also provides a blueprint for conducting an exchange (Macaulay 1963). This blueprint captures the roles and responsibilities of each party and documents mutual expectations that allow companies to align their actions (Mayer and Argyres
2004). Thus, a contract, like other forms of governance, is also an important coordination device (Gulati et al. 2005).

Effective contracts can help mitigate incentive conflicts and coordination problems among transacting parties, but writing such contracts is both cognitively challenging and costly. Given bounded rationality, it is problematic or even impossible to foresee all future relevant contingencies at the beginning of a transaction (Simon 1957). Hence, contracts necessarily leave out some relevant detail (Williamson 1975, 1985). However, repeated interactions on broadly similar transactions can help partners learn how to contract better. Organizations not only learn from each other (e.g., Hamel 1991), but they also learn how to collaborate with each other, such as in alliances (e.g., Doz 1996), networks (e.g., Dyer 1996), and mergers and acquisitions (e.g., Zollo and Singh 2004). Such learning is experiential, incremental, and largely partner specific (Doz 1996, Zollo et al. 2002, Zollo and Winter 2002).

Indicative of experiential learning, Mayer and Argyres (2004) find that contractual changes are primarily driven by actual problems experienced rather than by potential problems foreseen. These problems could arise from incentive conflict or from genuine misunderstandings. Even when relevant contingencies are identified, it may take several iterations to understand how these should be effectively addressed in a contract. The codification of this new knowledge in the contract enhances coordination by creating common knowledge among the contracting parties (Camerer and Knez 1996). Codification also guards against organizational forgetting and directly enhances the learning experience (Argote 1999, Zollo and Winter 2002). Further, codification in a contract leverages its potential enforceability, thus avoiding opportunistic attempts to renege on implicitly understood but noncontracted terms. Thus, because contracts can serve as repositories for knowledge about what and how to transact, and because such knowledge accumulates through repeated similar interactions, the task-specific components of contracts may become increasingly detailed as the relationship matures (Mayer and Argyres 2004, Ryall and Sampson 2009). We call this the learning effect - the tendency toward using more detailed contracts as a consequence of enhanced knowledge about what to specify in a contract that arises from repeated interactions between partners.

To avoid confounding learning with other consequences of repeated interaction between partners (such as trust), we focus in this paper on identifying the conditions under which the learning effect is likely to be stronger or weaker, leaving other aspects of the relationship (relatively) unchanged. If we can show that such conditions covary with changes in the extent to which contracts become more detailed with repeated interactions (i.e., changes to the marginal effects of prior interactions), then we can claim stronger evidence for the 
existence of the learning effect than is possible simply by examining the association between relationship history and contractual detail.

\section{Scope for Learning: Technical vs. Legal Clauses}

Contracts are complex documents with various types of clauses that range from standardized to transaction specific clauses (Macaulay 1963, Ben-Shahar and White 2006). The impact of prior interactions on the extent to which clauses are specified in detail is unlikely to be identical for these different kinds of clauses (Whang 1992, Ryall and Sampson 2009). We will argue that the effects of learning will be stronger on those clauses that are specific to the transaction. In particular, we will distinguish between technical and legal clauses and argue that the impact of prior interactions on contractual detail is greater on the former than on the latter.

Both technical and legal clauses can form part of a contract and have prima facie similar status in a court of law. However, they differ in their content. Technical clauses specify the requirements of the product or service being procured, such as the desired performance and functions (Whang 1992). These clauses are specific to the class of product, technology, and partner. Often technology specialists, not lawyers, are primarily responsible for drafting technical clauses (Argyres and Mayer 2007). As a result, organizations learn which contingencies are relevant to technical clauses from prior interactions involving the exchange of products of a similar nature.

Legal clauses are qualitatively different from technical clauses, as they specify the legal terms of trade, penalties, and dispute-resolution processes rather than the specifics of the goods and services being transacted (Whang 1992). To a large extent, these are standardized clauses based on existing templates and are drafted by lawyers who provide similar services to multiple firms (Macaulay 1963, Buskens 2002). A key implication of the distinction is that the same legal clauses can be applied to a wider range of transactions, whereas technical clauses-because of their transactionspecific nature-are only applicable in contracts for specific kinds of products. Organizations have substantially greater experience at transacting in general than at transacting a specific kind of product or service. Thus, when drafting a contract, an organization may draw on wideranging experiences that extend beyond the focal transaction for legal clauses. However, for technical clauses, an organization will have less relevant prior knowledge to build on.

These differences have implications for the value of an additional interaction in generating learning that can be used to specify more detailed contractual clauses, because learning from experience shows decreasing marginal returns (Yelle 1979, Dutton and Thomas 1984).
Because an organization is more likely to have higher levels of relevant experience for drafting legal clauses than technical clauses, and as the rate of learning declines with experience, we expect the learning effect to be stronger for technical clauses than for legal clauses. We can therefore predict a stronger learning effect in technical than in legal clauses; this should translate into a greater marginal effect of prior interactions on contractual detail.

HYPOTHESIS 1. The marginal effect of prior interactions on the detail with which technical clauses are specified will be greater than on the detail with which legal clauses are specified.

\section{Capacity for Learning: Expertise in the Technical Domain}

All firms may learn more about technical clauses through prior interactions of a similar nature, but the rate at which firms learn may differ. In particular, we argue that possession of expertise relevant to the domain of the products/services being procured can significantly leverage learning rates (Cohen and Levinthal 1990, Zahra and George 2002). Because learning occurs in part through building new associations between familiar concepts (Cohen and Levinthal 1990), being knowledgeable in a broader domain is often helpful when attempting to learn something specific. For example, students who are thoroughly familiar with algebra find it easier to understand advanced calculus topics (Ellis 1965). Likewise, when contracting parties possess competence relevant to the domain of what is being exchanged, they are more likely to benefit from the lessons of experience and extract insights about how to better specify technical clauses.

A supplier would typically have expertise relevant to the technical domain, but the same does not hold for a buyer. A buyer is not necessarily an expert in the products or services being bought (which is often the reason for buying in the first place) and therefore there is bound to be variation across buyers in the extent of relevant expertise they possess. If buyers with relevant expertise are able to extract more useful information from interactions than buyers without such expertise (Cohen and Levinthal 1990, Zahra and George 2002), then we would expect that for such buyers, the positive association between prior interactions and contractual detail will be even stronger.

In principle, the availability of relevant related expertise should enhance learning about both the technical and legal aspects of a transaction. However, given our arguments that learning plays a more important role in the specification of technical clauses than legal clauses (Hypothesis 1), we focus on the impact of relevant expertise on the detail with which technical clauses are specified. We therefore predict that the learning effect 
for technical clauses is stronger when the buyer possesses expertise in the relevant technical domain.

Hyротнеsis 2. A buyer's expertise in the technical domain positively moderates the marginal effect of prior interactions on the detail with which technical clauses are specified.

\section{Methods}

\section{Data}

We test our hypotheses on a sample of IT procurement transactions, which vary in the extent to which the transactors have engaged in similar transactions in the past. IT procurement transactions provide a good setting to study contractual detail because there is wide variation in transactional difficulties associated with the complexity of products and services being procured, coordination challenges, and switching costs (Lacity et al. 1995). Several prior studies of procurement and contracting are also set in this context, enabling comparability with our study (Poppo and Zenger 2002, Kalnins and Mayer 2004, Mayer and Argyres 2004). We use survey data on IT purchases by Dutch SMEs from the External Management of Automation database. In Dutch, "automation" is an umbrella term that covers all forms of IT supporting business processes. A group of researchers associated with Utrecht University collected the data (Batenburg and Raub 1995, Rooks et al. 1998) and made part of it publicly available through The Steinmetz Archive (www.dans.knaw.nl). The group also shared the nonpublic part of the data with us very generously.

The unit of analysis in this study is an IT purchase transaction, as reported by the buyer. The IT purchases in this data consist of software and/or hardware and vary from standard off-the-shelf products, such as administrative software and computers, to customized products, such as logistics software and networks. The SME buyers have between 5 and 200 employees and are active in a diverse range of industries, such as agriculture, construction, education, insurances, and transportation. All suppliers are from the IT industry.

The External Management of Automation database has two major advantages for the purposes of this study. First, across SMEs there is significant variation in IT expertise, reflecting differences in expertise in the product domain. The suppliers, being IT vendors, can all be expected to have IT expertise. This allows us to focus on the effects of variations in relevant expertise among the purchasing SMEs on contractual detail. Second, the SMEs do not have the capabilities to produce in house; nor do they have the financial means to integrate backward. In the survey about $96 \%$ of the buyers indicated that it was (very) difficult, if not impossible, to make the product/service they were procuring themselves. The make-buy decision is therefore exogenous to our framework, which lessens concerns about sample selection bias. In the survey each buyer was asked about a single IT transaction from a single IT supplier (see Batenburg 1997a for a complete survey description). The survey was administered in two periods, in 1995 and 1998.

To obtain sufficient variation on several key constructs, a random stratified sampling method was used in 1995. The sampling frame was constructed from Directview, a database of Dutch SMEs that is updated annually and that was estimated to have covered $80 \%$ of all Dutch SMEs. Three stratification criteria were used: (1) type of IT purchase-simple or complex and software or hardware, ${ }^{2}(2)$ number of IT specialists-none or some, and (3) interconnections in the industry-well linked versus poorly linked. A total of 1,325 SMEs that were suitable for the study were contacted. Of the firms contacted, 67\% agreed to cooperate. Of all firms that agreed to participate, $87 \%$ actually completed a survey (Batenburg 1997b). This resulted in a response rate of $59 \%$ for the first survey. An interviewer visited $83 \%$ of the respondents for data collection. For the remaining respondents, surveys were mailed. After finishing the survey, respondents were asked to fill in an additional survey on a different transaction, if possible, with the same supplier. No interviewer was present for these additional surveys. A total of 971 surveys were collected from 788 SMEs in 1995. Response analysis showed that non-participating firms did not differ significantly from participating firms on important characteristics such as size, industry, or region. Furthermore, a question asked during the initial contact revealed that they also did not differ in their general satisfaction with IT suppliers (Batenburg 1997b).

The second wave of data collection occurred in 1998. All participating firms from 1995 were contacted by phone; $84 \%$ could be reached (Rooks 2002). They were asked to fill out a new survey on a different product, but if possible from the same supplier. All surveys were sent by mail. An additional 281 transactions were collected in 1998 , which represented $36 \%$ of the buyers. After eliminating observations that did not meet the criteria of buyer size that defined an SME (5 to 200 employees) and respondent involvement necessary for a key informant $(61+56)$, we were left with a combined sample of 1,135 transactions by 788 buyers. On average each buyer had 1.4 transactions, with a maximum of 3 . The data do not allow us to uniquely identify suppliers. Missing values caused the number of observations to drop to between 840 and 761 in the analyses.

\section{Measures}

Most constructs are based on multiple items with fixed answer categories. Appendix A gives an overview of the questions used for the key constructs. The original 
questions were asked in Dutch. We conducted our own independent translation into English in addition to the translation provided by the survey authors to ensure their validity.

\section{Dependent Variables}

Technical detail is the extent to which technical specifications of the product or service being procured are specified in the contract. Respondents indicated the degree of specification on four items: security, user friendliness, definition of system boundaries, and definition of system functions. These items were constructed on the basis of analysis of contracts, discussion with lawyers, and a pilot test. For each item, a five-point answer scale ranged from "very broadly" to "very detailed." If an item did not apply, respondents were asked to indicate "not applicable." We decided to code "not applicable" as zero and to include those items in the analysis. In the robustness section we explore alternative specifications with respect to the coding of "not applicable." Technical detail is the standardized sum of responses to these four items, which is in line with previous research (Saussier 2000, Luo 2002). The scale has good reliability, with a Cronbach's alpha of 0.87 . The goodness of fit index from confirmatory factor analysis is 0.89 , which is satisfactory (Lattin et al. 2003).

Legal detail was measured through 10 items describing legal clauses of the transaction, such as liability of supplier, dispute resolution, and penalties on late payment. The items are given in Appendix A. As with items for technical detail, these items were also derived inductively. For each item, the respondent was asked to indicate whether it was "not arranged," "only orally arranged," or "arranged in writing." The frequency with which the legal clauses were arranged in writing ranges from $14 \%$ to $80 \%$ in our sample, with the median being $31.5 \%$. This indicates that these clauses were not merely boilerplate clauses that are always included irrespective of relevance. In the Dutch legal system, oral agreements are also legally binding but are much harder to prove in court than written agreements. Therefore, we code "not arranged" as zero, "oral agreement" as one, and "written agreement" as two. ${ }^{3}$ We measure legal detail as the standardized average of the scores on the 10 items. The reliability of the scale is good, with a Cronbach's alpha of $0.84 .^{4,5}$ Note that each item individually is not an appropriate measure of the detail with which a particular legal clause is specified, as an item indicates whether and how a particular clause was arranged. However, collectively the items should give a good indication of the legal detail of a contract or the extent to which legal clauses are specified. Thus, we can conceptually compare our aggregate measures of technical and legal detail. To enable statistical comparison of the effects of independent variables on technical and legal detail, we standardize both measures. In the robustness section, we discuss additional analyses that support the comparability of both measures.

\section{Independent Variables}

Prior interactions as a variable is measured as the number of times buyer and supplier had done business prior to the focal transaction (Gulati 1995, Buskens 2002, Corts and Singh 2004). Obtaining the precise number of prior interactions in survey-based studies of this nature is difficult. We relied instead on data from an item in which respondents indicated the number of times they interacted with the supplier in the past on a six-point scale ranging from "never" to "many times." this question was corroborated with another survey item in which respondents indicated the volume of business in prior interactions with the supplier. The correlation between these items was 0.92. About half the transactions in our data (54\%) involved a history of at least some prior interactions.

Expertise in the technical domain was captured by a dummy variable coding whether the procuring firm had any employees with expertise in IT (Boynton et al. 1994). Almost all SMEs indicated that they were unable to produce the product they were procuring in house, yet $56 \%$ of them had employees with IT expertise. Thus, this variable captures related but distinct knowledge in the technical domain. The suppliers were IT vendors, so we expected all of them to be competent in the technical domain.

\section{Control Variables}

We control for several characteristics of the transaction, buyer, and supplier that might impact the dependent and independent variables.

Transaction Characteristics. We control for transaction size with a measure of the financial volume of the transaction on a five-point scale. The boundaries of the qualitative categories are from fewer than 25,000 to more than 200,000 Dutch guilders (1 guilder is about 0.45 euro). We also control for type of product by inserting dummies for software and hardware. Respondents were asked to choose which products and services were included in the transaction from a list of 15 alternatives (multiple choices were allowed). These products and services broadly clustered into standard software, customized software, standard hardware, customized hardware, and additional services. We code a transaction as software when it has at least one software product and no hardware products. Similarly, we code a transaction as hardware when at least one hardware product is involved but no software products. The omitted category is transactions that have both software and hardware products. Only one transaction in the final sample had solely nonsoftware or nonhardware products (e.g., training). This 
transaction is included in the omitted category. ${ }^{7}$ Next, we include a measure of product complexity. Using the same list of 15 possible products, this measure is calculated as the sum of the different products or services included in the transaction. A more complex transaction is likely associated with more coordination and cooperation difficulties between buyer and supplier, which may be reflected in the contractual structure of the transaction (Gulati and Singh 1998). ${ }^{8}$

We include a measure of costs of failure to capture the perceived difficulties and costs involved in switching to a different product or supplier, in the event of a product failure (Batenburg et al. 2003). It is measured as the average of three items, in which the respondent indicates on a five-point scale (from "very little" to "very much") the magnitude of costs for a new product purchase, personnel training, and data reentry in the event of product failure (Cronbach's alpha $=0.75$ ). We include a measure of supplier alternatives to describe the extent of availability of alternative suppliers and products to the buyer before signing the contract. The availability of alternatives may substitute for contractual detail in controlling opportunism (Williamson 1975). The mean of two items with five-point scales (from "very few" to "very many") is used to measure the alternative possibilities the buyer faced in terms of products and suppliers (Cronbach's alpha $=0.74)$. We also include a measure selection difficulty to control for the possibility of adverse selection (Akerlof 1970). When it is difficult to assess the quality of a product, the buyer may want to invest more heavily in contractual detail as ex post protection. In contrast, it may be that in precisely such situations contractual detail is of less use because it is difficult to verify whether contractual clauses have been honored (Mayer 2006, Argyres et al. 2007). Therefore, we do not have a strong prior about the effect of this variable. The measure is constructed as the mean of three items that ask about the difficulty of evaluating the price/quality ratio of potential suppliers, comparing the product with other products, and assessing the product's quality at delivery. All items used five-point scales with the extreme answer categories of "very easy" and "very difficult." The Cronbach's alpha for this scale is 0.78 .

We control for expected future interactions, which make cooperation and reciprocity more likely. Expected future interactions may lead to less reliance on contractual detail for ensuring cooperation (Axelrod 1984). But a longer future may make it worth investing more heavily in additional safeguards (Williamson 1985). Therefore, we remain agnostic about the aggregate effect of expected future interactions. This is measured with a single item asking to what extent future interactions were expected at the time of contract signing. The extreme categories of the five-point answer scale are "not likely" and "very likely." We also insert dummies for the year of purchase to capture possible period effects. We control for the product's criticalness for buyer profits. If a product is very critical, the damage potential will be large and the buyer may want to limit the dangers by using a more detailed contract (Batenburg et al. 2003). This construct is captured by a single item with a five-point scale from "not important" to "very important" that asks: "How important was this product for the profitability of your firm?"

Buyer and Supplier Characteristics. We control for legal expertise of the buyer. This is measured by a dummy variable asking whether the firm had any employees with legal expertise (Buskens 2002). We also control for buyer size. This is measured as the natural $\log$ of the number of employees at the time of the purchase. Furthermore, we control for buyer's industry. We inserted dummies for the two-digit Dutch SBI codes of the buyer's industry, which are comparable to the American SIC codes. For the supplier we control for supplier size. This is measured on a five-point scale with boundaries of the qualitative categories from "less than 5" to "more than 50" employees.

\section{Results}

Table 1 reports the summary statistics and pairwise correlations between variables used in our analysis. The largest correlation is 0.75 between prior interactions and the interaction term of prior interactions and IT expertise. To assess potential collinearity concerns, we calculated variance inflation factors for all estimated models. These were well within acceptable limits.

Table 2 reports results from ordinary least squares (OLS) regression models for both technical and legal detail. We adjust the standard errors for possible nonindependence in our sample by clustering the observations of the same buyer. The first column (Model 1a) reports the base model of 840 observations for 581 different buyers consisting of only the control variables, with technical detail as the dependent variable. This base model is significant $\left(R^{2}=0.22, p<0.01\right)$. Firms with IT expertise, our measure of buyer's expertise relevant to the product domain, have more technically detailed contracts than firms without such expertise $(p<0.05)$. The size of the transaction, costs of failure, and the complexity and criticalness of the product are associated with greater technical detail. Pure hardware products have less technically detailed contracts than combined software and hardware products, and pure software products have the most technical detail. Selection difficulty has no effect on technical detail. It is possible that the additional protection from technical detail in such circumstances does not outweigh the difficulty of specifying them in our setting. The variable of expected future interactions is not significantly associated with technical detail. Again, it is feasible that in our setting, the longer payoff period for any safeguard investments does 


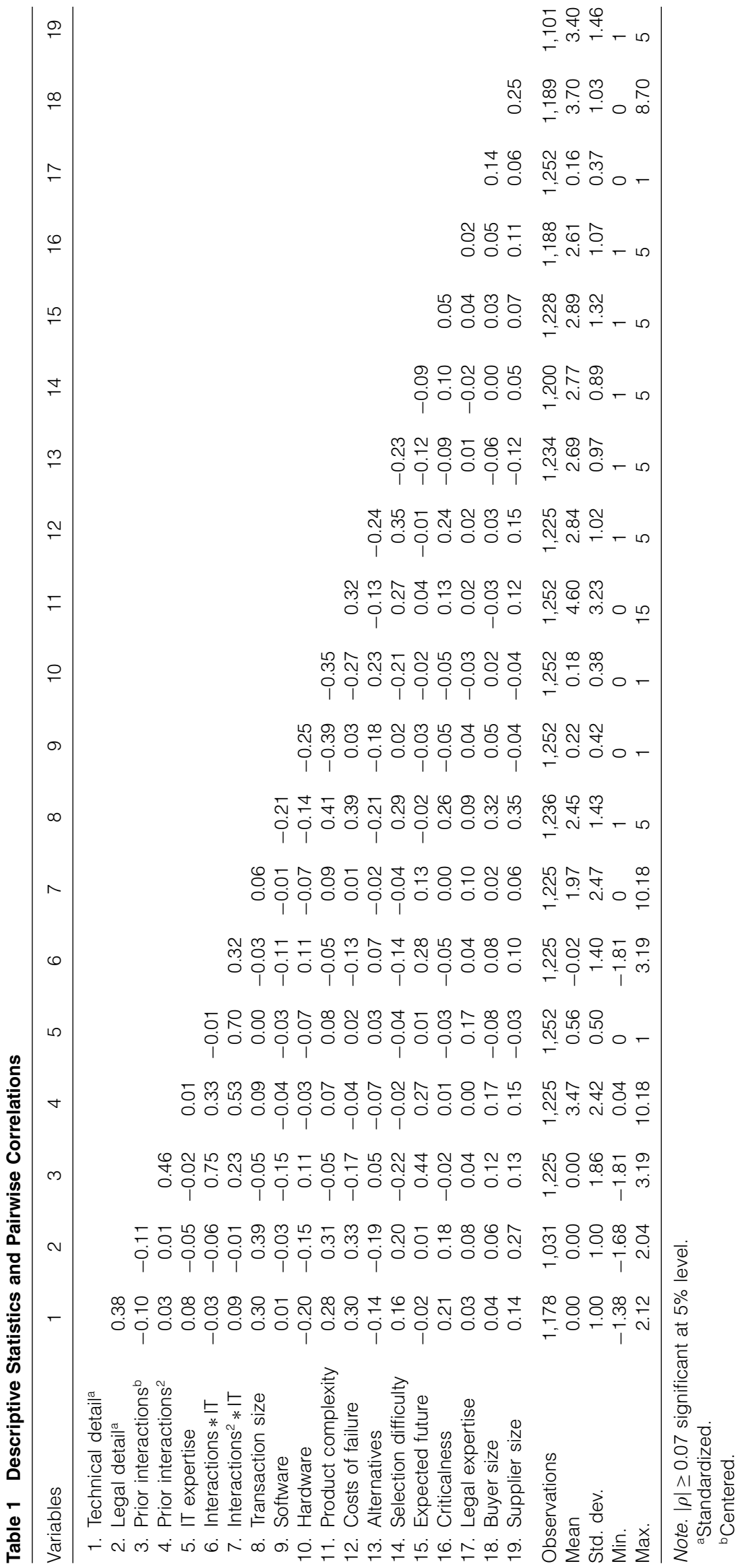


Table 2 Results of OLS Regression Analyses for Contractual Detail

\begin{tabular}{|c|c|c|c|c|c|c|}
\hline & Model 1a & Model 1b & Model 2a & Model 2b & Model 3a & Model 3b \\
\hline Variables & $\begin{array}{c}\text { Technical } \\
\text { detail }\end{array}$ & $\begin{array}{l}\text { Legal } \\
\text { detail }\end{array}$ & $\begin{array}{c}\text { Technical } \\
\text { detail }\end{array}$ & $\begin{array}{l}\text { Legal } \\
\text { detail }\end{array}$ & $\begin{array}{c}\text { Technical } \\
\text { detail }\end{array}$ & $\begin{array}{l}\text { Legal } \\
\text { detail }\end{array}$ \\
\hline Prior interactions & & & $\begin{array}{c}-0.04 \\
(0.02)^{*}\end{array}$ & $\begin{array}{c}-0.05 \\
(0.02)^{* *}\end{array}$ & $\begin{array}{l}-0.10 \\
(0.03)^{* * *}\end{array}$ & $\begin{array}{l}-0.08 \\
(0.03)^{* *}\end{array}$ \\
\hline Prior interactions ${ }^{2}$ & & & $\begin{array}{c}0.04 \\
(0.02)^{* *}\end{array}$ & $\begin{array}{c}0.01 \\
(0.02)\end{array}$ & $\begin{array}{c}0.05 \\
(0.02)^{* *}\end{array}$ & $\begin{array}{c}0.00 \\
(0.02)\end{array}$ \\
\hline Interactions $*$ IT & & & & & $\begin{array}{l}0.11 \\
(0.04)^{* * *}\end{array}$ & $\begin{array}{c}0.04 \\
(0.04)\end{array}$ \\
\hline Interactions ${ }^{2} *$ IT & & & & & $\begin{array}{c}-0.03 \\
(0.03)\end{array}$ & $\begin{array}{c}0.00 \\
(0.03)\end{array}$ \\
\hline IT expertise & $\begin{array}{c}0.14 \\
(0.07)^{* *}\end{array}$ & $\begin{array}{c}-0.06 \\
(0.07)\end{array}$ & $\begin{array}{c}0.14 \\
(0.07)^{*}\end{array}$ & $\begin{array}{c}-0.05 \\
(0.07)\end{array}$ & $\begin{array}{c}0.24 \\
(0.13)^{*}\end{array}$ & $\begin{array}{c}-0.07 \\
(0.13)\end{array}$ \\
\hline Transaction size & $\begin{array}{l}0.08 \\
(0.03)^{* *}\end{array}$ & $\begin{array}{l}0.11 \\
(0.03)^{* * *}\end{array}$ & $\begin{array}{l}0.08 \\
(0.03)^{* *}\end{array}$ & $\begin{array}{l}0.11 \\
(0.03)^{* * *}\end{array}$ & $\begin{array}{l}0.07 \\
(0.03)^{* *}\end{array}$ & $\begin{array}{l}0.11 \\
(0.03)^{* * *}\end{array}$ \\
\hline Software & $\begin{array}{l}0.28 \\
(0.10)^{* * *}\end{array}$ & $\begin{array}{l}0.27 \\
(0.11)^{* *}\end{array}$ & $\begin{array}{c}0.24 \\
(0.11)^{* *}\end{array}$ & $\begin{array}{c}0.22 \\
(0.11)^{*}\end{array}$ & $\begin{array}{c}0.24 \\
(0.10)^{* *}\end{array}$ & $\begin{array}{l}0.22 \\
(0.11)^{*}\end{array}$ \\
\hline Hardware & $\begin{array}{c}-0.18 \\
(0.11)^{*}\end{array}$ & $\begin{array}{c}0.05 \\
(0.10)\end{array}$ & $\begin{array}{c}-0.18 \\
(0.11)\end{array}$ & $\begin{array}{c}0.05 \\
(0.10)\end{array}$ & $\begin{array}{c}-0.19 \\
(0.11)^{*}\end{array}$ & $\begin{array}{c}0.04 \\
(0.10)\end{array}$ \\
\hline Product complexity & $\begin{array}{l}0.06 \\
(0.01)^{* * *}\end{array}$ & $\begin{array}{l}0.07 \\
(0.01)^{* * *}\end{array}$ & $\begin{array}{l}0.06 \\
(0.01)^{* * *}\end{array}$ & $\begin{array}{l}0.07 \\
(0.02)^{* * *}\end{array}$ & $\begin{array}{l}0.06 \\
(0.01)^{* * *}\end{array}$ & $\begin{array}{l}0.07 \\
(0.02)^{* * *}\end{array}$ \\
\hline Costs of failure & $\begin{array}{l}0.16 \\
(0.04)^{* * *}\end{array}$ & $\begin{array}{l}0.14 \\
(0.04)^{* * *}\end{array}$ & $\begin{array}{l}0.16 \\
(0.04)^{* * *}\end{array}$ & $\begin{array}{l}0.13 \\
(0.04)^{* * *}\end{array}$ & $\begin{array}{l}0.16 \\
(0.04)^{* * *}\end{array}$ & $\begin{array}{l}0.13 \\
(0.04)^{* * *}\end{array}$ \\
\hline Alternatives & $\begin{array}{c}-0.04 \\
(0.04)\end{array}$ & $\begin{array}{c}-0.06 \\
(0.04)\end{array}$ & $\begin{array}{c}-0.04 \\
(0.04)\end{array}$ & $\begin{array}{c}-0.06 \\
(0.04)\end{array}$ & $\begin{array}{c}-0.04 \\
(0.04)\end{array}$ & $\begin{array}{c}-0.06 \\
(0.04)\end{array}$ \\
\hline Selection difficulty & $\begin{array}{c}-0.03 \\
(0.04)\end{array}$ & $\begin{array}{c}-0.00 \\
(0.04)\end{array}$ & $\begin{array}{c}-0.03 \\
(0.04)\end{array}$ & $\begin{array}{c}0.00 \\
(0.04)\end{array}$ & $\begin{array}{c}-0.04 \\
(0.04)\end{array}$ & $\begin{array}{c}0.00 \\
(0.04)\end{array}$ \\
\hline Expected future & $\begin{array}{c}-0.01 \\
(0.03)\end{array}$ & $\begin{array}{c}-0.01 \\
(0.03)\end{array}$ & $\begin{array}{c}0.00 \\
(0.03)\end{array}$ & $\begin{array}{c}0.02 \\
(0.03)\end{array}$ & $\begin{array}{c}0.00 \\
(0.03)\end{array}$ & $\begin{array}{c}0.02 \\
(0.03)\end{array}$ \\
\hline Criticalness & $\begin{array}{l}0.09 \\
(0.03)^{* * *}\end{array}$ & $\begin{array}{c}0.04 \\
(0.04)\end{array}$ & $\begin{array}{l}0.09 \\
(0.03)^{* * *}\end{array}$ & $\begin{array}{c}0.04 \\
(0.04)\end{array}$ & $\begin{array}{l}0.10 \\
(0.03)^{* * *}\end{array}$ & $\begin{array}{c}0.04 \\
(0.04)\end{array}$ \\
\hline Legal expertise & $\begin{array}{c}-0.08 \\
(0.10)\end{array}$ & $\begin{array}{c}0.12 \\
(0.10)\end{array}$ & $\begin{array}{c}-0.06 \\
(0.09)\end{array}$ & $\begin{array}{c}0.12 \\
(0.10)\end{array}$ & $\begin{array}{c}-0.07 \\
(0.09)\end{array}$ & $\begin{array}{c}0.12 \\
(0.10)\end{array}$ \\
\hline Buyer size & $\begin{array}{c}-0.00 \\
(0.05)\end{array}$ & $\begin{array}{l}-0.10 \\
(0.05)^{* *}\end{array}$ & $\begin{array}{c}-0.00 \\
(0.05)\end{array}$ & $\begin{array}{c}-0.09 \\
(0.05)^{*}\end{array}$ & $\begin{array}{c}-0.00 \\
(0.05)\end{array}$ & $\begin{array}{c}-0.09 \\
(0.05)^{*}\end{array}$ \\
\hline Supplier size & $\begin{array}{c}0.02 \\
(0.03)\end{array}$ & $\begin{array}{l}0.13 \\
(0.03)^{* * *}\end{array}$ & $\begin{array}{c}0.02 \\
(0.03)\end{array}$ & $\begin{array}{l}0.13 \\
(0.03)^{* * *}\end{array}$ & $\begin{array}{c}0.02 \\
(0.03)\end{array}$ & $\begin{array}{l}0.13 \\
(0.03)^{* * *}\end{array}$ \\
\hline Industry dummies & yes & yes & yes & yes & yes & yes \\
\hline Year of purchase dummies & yes & yes & yes & yes & yes & yes \\
\hline Constant & $\begin{array}{c}-0.84 \\
(0.43)^{*}\end{array}$ & $\begin{array}{c}-0.74 \\
(0.45)^{*}\end{array}$ & $\begin{array}{c}-0.98 \\
(0.44)^{* *}\end{array}$ & $\begin{array}{l}-0.88 \\
(0.45)^{* *}\end{array}$ & $\begin{array}{l}-1.06 \\
(0.43)^{* *}\end{array}$ & $\begin{array}{c}-0.86 \\
(0.45)^{*}\end{array}$ \\
\hline Observations & 840 & 765 & 835 & 761 & 835 & 761 \\
\hline d.f. & 60 & 60 & 62 & 62 & 64 & 64 \\
\hline$F$ & $5.77^{* * *}$ & $9.22^{* * *}$ & $6.19^{* * *}$ & $9.55^{* * *}$ & $6.42^{* * *}$ & $9.47^{* * *}$ \\
\hline$R^{2}$ & 0.22 & 0.31 & 0.23 & 0.31 & 0.24 & 0.31 \\
\hline
\end{tabular}

Note. Robust standard errors with clustering for same buyer in parentheses. Significance marks and standard errors are based on a common robust covariance matrix for technical and legal detail.

${ }^{*} p<0.10,{ }^{* *} p<0.05,{ }^{* * *} p<0.01$ in a two-tailed test.

not outweigh the assurance generated through the potential value of future interactions. The remaining controls, alternatives, legal expertise, and buyer and supplier size are not significant.

The second column (Model 1b) shows the same base model but with legal detail as the dependent variable. The number of observations is slightly lower: 765 for
543 different buyers. This base model is also significant $\left(R^{2}=0.31, p<0.01\right)$. The effect of the control variables on legal detail is largely similar to that on technical detail, though intuitively, legal expertise is associated with more legal detail but not more technical detail. Conversely, IT expertise is not associated with more legal detail. Also, firm size affects legal but not technical 
detail. Interestingly, a larger buyer is associated with less legal detail, but a larger supplier is associated with more legal detail. If these factors can be taken as indicators for market power, this finding would suggest that depending on who has more power the effect on legal detail is different.

In Model 2a, with technical detail as the dependent variable, we add our measure of prior interactions as well as its squared term to allow for possible curvilinearity - it is well established that learning from experience shows decreasing marginal returns (Yelle 1979, Dutton and Thomas 1984). For this and subsequent models of technical detail, the number of different buyers remains unchanged, but because of missing data the number of observations drops to 835 . The linear term of prior interactions is negative $(p=0.08)$, and the squared term is positive $(p=0.03)$. To explore differences in type of contractual clauses, we estimate the same model specification, except with legal detail as the dependent variable. The number of observations for this and following models of legal detail is 761 , and the number of different buyers is 541. We find that prior interactions have a negative direct effect on legal detail $(p=0.02)$, and the squared term of prior interactions is not significant $(p=0.72)$. The absence of an upward sloping component to the effect of prior interactions on legal detail could be because learning for legal detail is not only weaker than for technical detail (as we argue in Hypothesis 1), but is weak in absolute terms.

Figure 1 plots the estimated relationship between prior interactions on the one hand and technical detail (full line) or legal detail (dotted line) on the other. The difference between technical and legal detail is striking. For technical detail, the effect of prior interactions is not only curvilinear but is in fact nonmonotonic-i.e., there is a stationary point at which the curve has a minimum, resulting in a U-shaped relationship. Technical detail initially decreases significantly with prior interactions $(p<0.02$ at prior interactions at the low end of the

Figure 1 Effect of Prior Interactions on Technical and Legal Detail

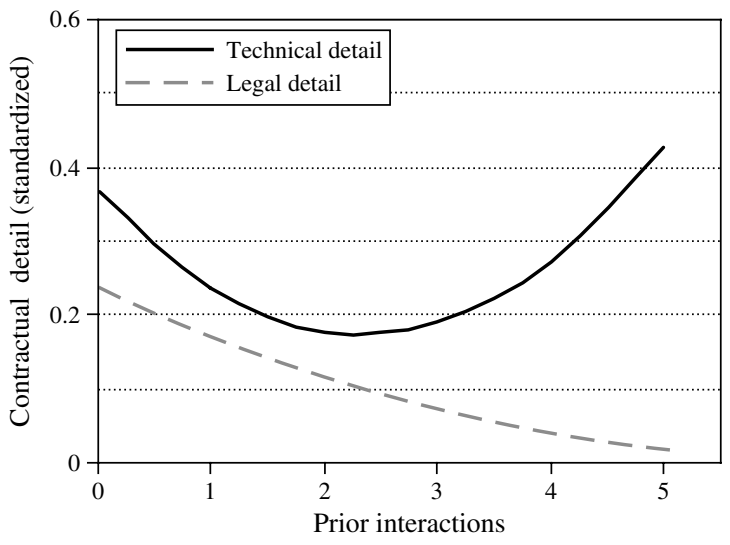

scale), and for high levels of prior interactions this effect reverses ( $p<0.06$ at prior interactions at the high end of the scale). It is possible that at low levels of prior interaction, the learning effect is dominated by some other consequence of relationship history that creates a decline in contractual detail (e.g., trust as discussed by Gulati 1995). In contrast, for legal detail we find no evidence for an upward sloping (learning) component, or at least if it exists, it is perhaps dominated by a trust effect. Note that in the figure the axis of prior interactions represents qualitative categories (from "never" to "many times"), which cannot be interpreted as exact numbers.

In Hypothesis 1 we predict a greater marginal effect of prior interactions on technical detail than on legal detail. Graphically, this claim seems supported, as there are no increases in legal detail with increasing interactions, but there is at least some range of prior interactions over which technical detail increases. We turn to quantitative evidence to formally support or reject the hypothesis. Because technical and legal detail are standardized, the effect of prior interactions on both is directly comparable. The marginal effect of prior interactions on either technical or legal detail, $\beta 1+2 \beta 2 *$ (Prior_interactions) (Models $2 \mathrm{a}$ and $2 \mathrm{~b}$ ), indicates how many standard deviations either technical or legal detail changes per one unit increase on the prior interactions scale. The difference in marginal effect of prior interactions on technical and legal detail is not constant because of the nonmonotonic effect for technical detail. As is usual for nonlinear functions, to test Hypothesis 1, we evaluate the difference in marginal effects at the mean of the number of prior interactions. This is a conservative test in the sense that a difference at the mean supports the hypothesis of different marginal effects, but no difference at the mean could still be consistent with differences at other points over the range of the independent variable. To statistically compare the marginal effects across models, we obtain the joint variance-covariance matrix to allow the errors of both models to be correlated.

We find that the difference in marginal effects at the mean of prior interactions is positive in favor of technical detail, but statistically the difference is not significant (nor for values below the mean). However, for levels of prior interactions above the mean, the marginal effect of prior interactions on technical detail is marginally significantly greater than on legal detail $(0.05<p<0.08)$. Specifically, at high levels of prior interactions, with an additional increment in prior interactions, legal detail would decrease a mere 0.01 standard deviation. In contrast, technical detail would increase no less than 0.19 standard deviations. Thus, Hypothesis 1 is weakly supported for the upper range of prior interactions. The marginal effect of prior interactions is larger on technical than on legal detail, though the difference occurs at higher levels of prior interactions. 
We turn to Model 3a to test whether a buyer's expertise in the product domain increases the marginal effect of prior interactions on the detail of technical clauses (Hypothesis 2). Model 3a includes the interactions of IT expertise with the linear and squared term of prior interactions on technical detail. A joint test of the interaction terms of IT expertise with the linear and squared term of prior interactions shows that IT expertise moderates the relationship between prior interactions and technical detail $(p=0.02)$. In particular, the interaction effect of IT expertise with the linear term of prior interactions is strongly positive $(p<0.01)$. To test Hypothesis 2, we evaluate whether a buyer's expertise in the product domain increases the marginal effect of prior interactions at the mean of prior interactions. As before, this is a conservative test in the sense that a difference at the mean supports the hypothesis of different marginal effects, but no difference at the mean could still be consistent with differences at other points over the range of the independent variable. The marginal effect of prior interaction on technical detail in this model is $\beta 1+2 \beta 2 *$ Prior_interactions $+\beta 4 *$ IT_expertise $+2 \beta 5 *$ Prior_interactions $*$ IT_expertise (Model 3a), obtained by taking the first derivate of technical detail with respect to prior interactions. We find that the marginal effect of prior interactions is significantly greater for firms with IT expertise than for firms without such expertise at the mean of prior interactions $(p<0.01)$. Thus, Hypothesis 2 is supported. The moderation effect of IT expertise on the relationships between prior interactions and technical detail is shown in Figure 2.

For completeness, we also present the results for legal detail in Model 3b. Neither the interaction of IT expertise with the linear term of prior interactions $(p=0.27)$ nor the interaction with the squared term of prior interactions is significant $(p=0.93)$. Also, they are not jointly significant $(p=0.43)$. Hence, IT expertise does

\section{Figure 2 Moderation Effect of IT Expertise on Prior Interactions and Technical Detail}

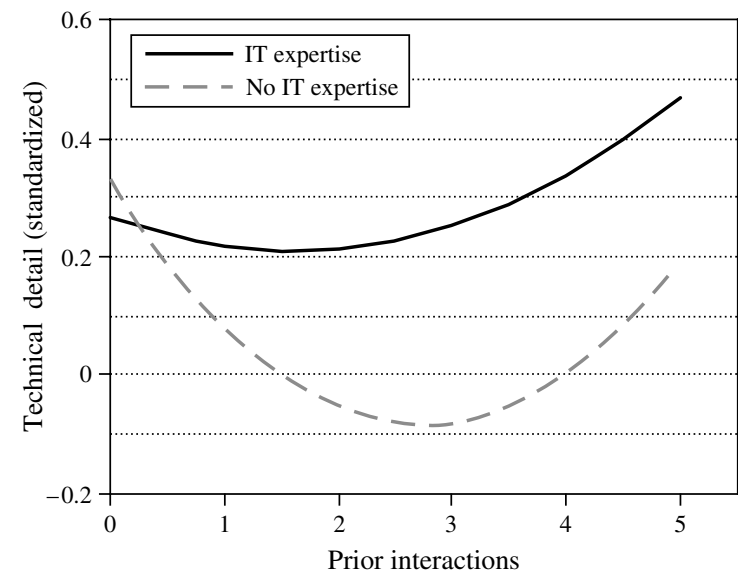

not moderate the impact of prior interactions on legal detail. $^{9}$

\section{Robustness Checks}

Like most studies of procurement relationships (e.g., Artz and Brush 2000, Poppo and Zenger 2002, Gulati et al. 2005), our study employs data from a single respondent from the buying company for each transaction. To limit the concerns about respondent bias, we reestimated all models with an added control: the respondent's employment duration with the firm (Kumar et al. 1993). This control was not significant, nor did it change any of the results. A single respondent may in general cause concern about common method bias (Podsakoff et al. 2003), but this does not appear to be an issue in our study. Common method bias alone cannot explain the nonmonotonic effect of prior interactions on technical detail, nor can it explain the interaction effect of IT expertise. In the latter case, this would amount to saying that the common method bias is stronger in one half of the sample (firms with IT expertise) than in the other (firms without such expertise), and in the case of the former, the bias would have to vary in magnitude and direction with the number of prior interactions. Hence, from a conceptual standpoint, common method bias does not seem like a significant threat to the validity of our results. Nonetheless, we applied Harman's onefactor test on the underlying items to assess possible common factors (Harman 1967, Podsakoff and Organ 1986). We found that the dependent and independent variables did not load on the same factor, and no single factor explained a majority of the variance. Therefore, common method bias does not drive our results.

To control for any systematic distortion caused by our reliance on retrospective data, we also included a control for the age of the transaction, which is the time in years between the purchase of the product and the survey. The control was not significant and did not influence our results. In addition, we explored whether variations in data collection affected our results. The surveys were collected in 1995 and in 1998, and for some a researcher was present. We inserted dummies for the year of survey and for the presence of a researcher. Adding these controls did not change our results.

Because for each individual technical clause a considerable number of observations score zero (i.e., not applicable), we reestimated all models with a Tobit specification. Nonapplicability is treated as endogenous in Tobit models. For this specification we coded the aggregate measure as not applicable if any of the technical clauses was zero. The results were in line with those of OLS. Furthermore, Tobit analyses on individual technical items gave results largely consistent with those reported here. We choose to report the latter, because OLS is much more robust to violations of distributional assumptions. In addition, we also estimated a Heckman 
model for technical detail as a different way to account for the possibility that different processes drive applicability and detail conditional on applicability. We found no evidence in our setting to support this. We can therefore treat "not applicable" as a low value of detail as we do in the OLS results.

Because technical and legal detail are measured in different ways, we also recoded technical detail in ways such that it more closely matches legal detail (which is based on the presence of individual clauses). We dichotomized each technical clause by coding it as one when present and as zero when absent (similar to legal clauses). ${ }^{10}$ We ran logit models on three different measures: (1) on the individual clauses; (2) on an aggregate measure, which is one only if all four technical clauses are present; and (3) on an aggregate measure, which is one if at least one technical clause is present. The logit results for aggregate and individual technical measures yielded similar results as those we present here. Finally, we also ran OLS models on a continuous aggregate measure of technical detail, which was the standardized average of the four dichotomized clauses. Effect sizes were comparable, though significance levels were lower (because of reduced variance). Hence, it seems appropriate to directly compare technical and legal detail. Nonetheless, we acknowledge the limitations of our legal detail measure. Future research would surely benefit from measuring the extent of detail in both clauses on a more directly comparable basis.

\section{Discussion}

In this study, our goal has been to broaden our understanding of how contractual detail is shaped by prior interactions between contracting parties. To disentangle the learning effect from other possible consequences of prior interactions, we focused on conditions when the learning effect was relatively stronger. Further, given prior findings of both positive and negative associations between prior interactions and contractual detail, we opted to study changes in the marginal effects of prior interactions on contractual detail as a function of predicted differences in the magnitude of the learning effect. Although the findings for the differences between clauses (Hypothesis 1) are weaker than those for IT expertise (Hypothesis 2), together they demonstrate the existence of a learning effect. In the light of the difficulty of obtaining detailed contract data, these findings also provide a promising initial attempt to understand when the learning effect is likely to be particularly strong (or weak).

Our findings suggest some speculations about other possible consequences of prior interactions as well. Our results indicate both downward sloping and upward sloping components to the relationship between prior interactions and technical detail in contracts. This is not the case for legal clauses, where we find no evidence of an upward sloping relationship at all. Instead, we find that prior interactions decrease the amount of legal detail, consistent in spirit with some prior work, such as Batenburg et al. (2003) and Buskens (2002). These findings support our hypothesis of stronger learning effects on technical clauses, but this also suggests that learning dominates other consequences of relationship history that might discourage the use of detailed contracts for high levels of interaction in technical clauses, but not in legal clauses. Thus, it is useful to distinguish different kinds of contractual clauses on the basis of the potential for experience to generate new insights.

We also find that the learning effect on technical detail is enhanced (positively moderated) by expertise in the product domain. We found that relevant expertise increased the learning effect to such an extent that the upward sloping portion of the relationship commenced for fewer prior interactions. The presence of relevant expertise for the transacting firms thus affects the role of contracts within their relationships-for such firms formal contracts gain more rapidly in importance.

\section{Trust: An (Unobserved) Alternative Explanation?}

Our findings indicating a negative relationship between prior interactions and contractual detail (at low levels of prior interactions for technical detail and at all levels of prior interactions for legal detail) may suggest to some scholars the possibility of a trust effect (Crocker and Reynolds 1993, Parkhe 1993, Gulati 1995, Corts and Singh 2004). In this section, we discuss whether it is possible for our findings to be explained by such a trust effect alone, without need for our hypothesized learning effect. We acknowledge that because we do not directly study trust or its moderators, we cannot state with certainty that the downward sloping portion of the relationship we uncover between prior interactions and contractual detail is solely due to trust. However we will speculate about whether arguments rooted in trust alone could be sufficient to explain our findings (invalidating the need to invoke learning at all) even if one were to assume that the downward sloping portion of our relationships between prior interactions and contractual detail arose purely from increasing levels of trust.

In the spirit of Stinchcombe (1987), we contrast the empirical findings with our theory based on learning (possibly coexisting with trust) and with that of a theory based on trust alone (see Table 3). We find that a "trust only" story can possibly explain just the U-shaped effect of prior interactions on technical detail, if one makes an ad hoc assumption that the trust effect is initially negative and eventually positive (Finding I). However, in that case, trust alone cannot explain our other three findings. As technical and legal clauses feature in the same contract and affect the same partners, courts 
Table 3 Alternative Explanations

\begin{tabular}{|c|c|c|c|c|}
\hline Finding & Hypothesis & $\begin{array}{l}\text { Our interpretation } \\
\text { Learning (possibly } \\
\text { coexisting with trust) }\end{array}$ & $\begin{array}{c}\text { Alternative explanation } 1 \\
\text { Trust only }\end{array}$ & $\begin{array}{c}\text { Alternative explanation } 2 \\
\text { Positive and negative learning only }\end{array}$ \\
\hline $\begin{array}{l}\text { (I) Prior interactions has a } \\
\text { U-shaped effect on } \\
\text { technical detail. }\end{array}$ & $\begin{array}{l}\text { Nonhypothesized } \\
\text { finding }\end{array}$ & $\begin{array}{l}\text { Consistent-with a } \\
\text { learning effect that } \\
\text { is initially } \\
\text { dominated by a } \\
\text { negative trust } \\
\text { effect. }\end{array}$ & $\begin{array}{l}\text { Consistent-with the } \\
\text { additional assumption } \\
\text { that trust has a negative } \\
\text { effect for low values of } \\
\text { prior interactions and a } \\
\text { positive one for high } \\
\text { values. }\end{array}$ & $\begin{array}{l}\text { Consistent-with the additional } \\
\text { assumption that learning has a } \\
\text { negative effect for low values of } \\
\text { prior interactions and a positive } \\
\text { effect for high values. }\end{array}$ \\
\hline $\begin{array}{l}\text { (II) Marginal effect of prior } \\
\text { interactions greater on } \\
\text { technical than on legal } \\
\text { detail for high values } \\
\text { of prior interactions. }\end{array}$ & $\begin{array}{l}\text { H1: The marginal } \\
\text { effect of prior } \\
\text { interactions is } \\
\text { greater on } \\
\text { technical than } \\
\text { legal detail. }\end{array}$ & $\begin{array}{l}\text { Consistent-at lower } \\
\text { values of prior } \\
\text { interactions a } \\
\text { strong negative } \\
\text { trust effect may } \\
\text { mask differences } \\
\text { in learning. }\end{array}$ & $\begin{array}{l}\text { Inconsistent-technical } \\
\text { and legal detail feature } \\
\text { in same contract and } \\
\text { should be similarly } \\
\text { affected by prior } \\
\text { interactions. }\end{array}$ & $\begin{array}{l}\text { Inconsistent-if legal detail is initially } \\
\text { downward sloping due to } \\
\text { negative learning, then legal } \\
\text { detail should increase for high } \\
\text { values of prior interactions (like } \\
\text { technical detail (see I)). }\end{array}$ \\
\hline $\begin{array}{l}\text { (III) Marginal effect of } \\
\text { prior interactions on } \\
\text { technical detail } \\
\text { stronger with IT } \\
\text { expertise at mean of } \\
\text { prior interactions. }\end{array}$ & $\begin{array}{l}\text { H2: IT expertise } \\
\text { positively } \\
\text { moderates the } \\
\text { marginal effect of } \\
\text { prior interactions } \\
\text { on technical } \\
\text { detail. }\end{array}$ & Consistent. & $\begin{array}{l}\text { Inconsistent-if IT } \\
\text { expertise leads to more } \\
\text { trust and trust has a } \\
\text { negative effect initially } \\
\text { (see I), then marginal } \\
\text { effect of prior interaction } \\
\text { should be lower with IT } \\
\text { expertise. }\end{array}$ & $\begin{array}{l}\text { Inconsistent-if a flip in the learning } \\
\text { effect exists (see I), then IT } \\
\text { expertise should negatively } \\
\text { moderate prior interactions initially } \\
\text { (which is not the case) and } \\
\text { positively moderate for high } \\
\text { values. }\end{array}$ \\
\hline $\begin{array}{l}\text { (IV) Marginal effect of } \\
\text { prior interactions on } \\
\text { legal detail the same } \\
\text { with or without IT } \\
\text { expertise. }\end{array}$ & $\begin{array}{l}\text { Nonhypothesized } \\
\text { finding }\end{array}$ & $\begin{array}{l}\text { Consistent-learning } \\
\text { effect on legal } \\
\text { detail is itself small. }\end{array}$ & $\begin{array}{l}\text { Inconsistent-if IT } \\
\text { expertise affects trust, } \\
\text { then marginal effect of } \\
\text { prior interactions should } \\
\text { be different. }\end{array}$ & $\begin{array}{l}\text { (Possibly) consistent-if IT expertise } \\
\text { is not relevant for leveraging } \\
\text { learning in legal clauses. } \\
\text { However, inconsistent with the } \\
\text { finding that legal expertise does } \\
\text { not moderate the effect of prior } \\
\text { interactions on legal detail. }\end{array}$ \\
\hline
\end{tabular}

will not distinguish between them in terms of enforceability. Therefore, the trust effect should operate equally on both technical and legal clauses. This is not consistent with the different effect of prior interactions on technical and legal detail (Finding II). Also, even if IT expertise leads to higher trust-e.g., because of a shared organizational category and adherence to the same rules and norms (Kramer 1999) - and the trust effect is initially negative (necessary to explain Finding I), then the marginal effect of prior interaction on technical detail should be lower with IT expertise. This is inconsistent with Finding III. Finally, if IT expertise affects the level of trust, then the marginal effect of prior interactions on legal detail should be different in the presence or absence of IT expertise. We find no difference (Finding IV).

In contrast, our theory of learning (possibly in conjunction with trust) is consistent with all four findings. The U-shaped effect is consistent with a learning effect that is initially masked by a trust effect (Finding I). Findings II and III are consistent with our hypotheses. Finally, the absence of an IT moderation effect of prior interactions on IT expertise is consistent with the argument that the learning effect on legal detail is small
(Finding IV). In conclusion, trust alone cannot explain our results. Our evidence is strongly supportive of a learning effect that operates more strongly for certain kinds of clauses and transactors, as we have argued it should. This is not to rule out the possible simultaneous operation of a trust effect. ${ }^{11}$

\section{Limitations and Possible Extensions}

Like any research, our study also has some limitations. Our arguments about the moderating impact of relevant expertise assume that it only affects the learning effect, not other consequences of repeated interaction (i.e., trust). Although this is a reasonable assumption at a conceptual level, our coarse-grained measure, which captures the presence of employees in the buyer firm with IT expertise, may violate this assumption. As we note in Table 3, we do not find evidence for this because IT expertise does not moderate the relationship between prior interactions and legal detail. Nonetheless, we do believe that further examination of the complex relationships between learning, trust formation, and coordination would prove both theoretically and empirically fruitful. Furthermore, such research would undoubtedly benefit from a more direct measurement of drivers of learning. 
Despite several robustness checks we conducted, we also believe that this line of research would benefit from longitudinal data. This would allow us to confirm that IT expertise is strengthening learning from prior interactions and to rule out the possibility that firms strengthen their expertise after technically detailed contracts are written. Also, with longitudinal data, the accuracy of the measures would not be threatened by retrospective bias.

Our findings also suggest some directions for future research into the relationships between trust, learning, and contractual complexity. If we assume that the negative relationships we uncovered between prior interactions and contractual detail are indeed driven by increasing trust, then several intriguing possibilities arise for further research. For instance, a minimal level of trust may be necessary before any learning is feasible. This might explain why the learning effect only dominates in our sample at higher level of prior interactions. Relatedly, the learning effect may become more powerful when it is leveraged by trust; that would account for the sharply upward sloping portion of the relationship between prior interactions and contractual detail. ${ }^{12}$ A corollary to these propositions is that even if trust in relationships is high, contracts could still be highly detailed. This is consistent with the findings of Poppo and Zenger (2002), who find in their study of IT procurement that longevity of a relationship is positively correlated with the closeness of the relationship, which in turn is positively related to contractual complexity. If the "trust first, learning later" pattern we speculated on above proves to be valid, this would also suggest that whether trust and contractual detail are positively related could depend on the average number of prior interactions in the sample, as trust and contractual detail could be negatively related for low numbers of prior interactions but positively for high numbers. This could provide a rationale for why some prior studies find a negative correlation between measures of prior interactions (as proxies for trust) and contractual detail (e.g., Parkhe 1993), but others report a positive correlation (e.g., Ryall and Sampson 2009). This would reinforce our contention that it is not possible to make first-order predictions about the relationship between prior interactions and contractual detail.

Another valuable empirical extension would be to explicitly incorporate data about the supplier and its characteristics, as both parties influence the contracting process and its outcome. Where we have focused on buyer characteristics, future research may, for example, explore the effects of the supplier's familiarity with the buyer's products and processes on contractual detail. Reflecting on these limitations and potential extensions, we remain convinced that further research into the role of contracts as coordination devices and an analysis of the mechanisms by which they change over time is an extremely fruitful area for research.

\section{Conclusion}

The economic literature on contracting as well as its sociologically rooted criticisms (Granovetter 1985, Ring and Van de Ven 1992, Gulati 1995) share a common view of contracts-that they are primarily a means to minimize the consequences of incentive conflict. Yet contracts also perform an important coordinative function by establishing common ground and shared understanding about the transaction. ${ }^{13}$ In one of the seminal papers on contracting, Macaulay notes that lawyers often complain that "businessmen desire to 'keep it simple and avoid red tape' even when large amounts of money and significant risks are involved. One stated that he was sick of being told 'We can trust old Max,' when the problem is not one of honesty but one of reaching an agreement that both sides understand" (1963, pp. 58-59, emphasis added). Prior interactions between the same partners provide an important means by which such shared understanding can build up, and the contract can function as a focal repository for such knowledge (Mayer and Argyres 2004). Hence, the learning effect is very relevant even if the contracting parties trust each other. The empirical challenge lies in being able to disentangle the learning effect from other consequences of relationship history, such as trust, which some studies suggest leads to less detailed contracts.

This study tackles the problem of identifying the learning effect by focusing on the conditions under which the learning effect is likely to be stronger and on changes in the marginal effects of prior interactions as a consequence. We show that the learning effect is stronger for technical than for legal clauses in contracts and is stronger for firms with technical expertise relevant to the product domain than for firms without such expertise. In sum, learning effects may result in more detailed contracts between partners interacting repeatedly when there is much to be learned through repeated interactions, and it can be learned effectively.

\section{Acknowledgments}

The authors are grateful to the ISCORE group of the Faculty of Sociology of Utrecht University for providing access to their data, and in particular to Vincent Buskens, Werner Raub, Gerrit Rooks, and Chris Snijders for insightful discussions. The authors thank seminar participants at INSEAD, the London Business School, Tanaka Business School, University of Southern Denmark, and Utrecht University, and Julie Davidson, Manuel Hensmans, Madan Pillutla, Maurice Schellekens, Kannan Srikanth, Catalina Stefanescu, Wendy van der Valk, and Freek Vermeulen for helpful comments. The authors also appreciate the insightful and constructive comments of the editor Bill McEvily and the reviewers. Puranam acknowledges funding from the Mack Center for Technological Innovation at the Wharton School. Vanneste gratefully acknowledges a Marie Curie Fellowship with the European Union. The views presented in this article are not necessarily the views of the European Commission. 


\section{Appendix A. Key Constructs}

\begin{tabular}{|c|c|}
\hline Construct & Items \\
\hline Technical detail & $\begin{array}{l}\text { Indicate for each topic the extent of specification in the main contract: } 1=\text { very broadly, } \\
5=\text { very detailed. (If a certain technical aspect does not apply, indicate "not applicable.") } \\
\begin{array}{ll}\text { (a) Security } & \text { (c) Definition (of) system boundaries } \\
\text { (b) User friendliness } & \text { (d) Definition (of) system functions }\end{array}\end{array}$ \\
\hline Legal detail & $\begin{array}{l}\text { Indicate for each topic whether it was not arranged (0), only orally arranged (1), or } \\
\text { arranged in writing (2). } \\
\begin{array}{ll}\text { (a) Penalties on late payment } & \text { (f) Nondisclosure user } \\
\text { (b) Liability supplier } & \text { (g) Insurance supplier } \\
\text { (c) Force majeure supplier } & \text { (h) Duration service } \\
\text { (d) Warranties supplier } & \text { (i) Dispute resolution } \\
\text { (e) Intellectual property (escrow) } & \text { (j) Terms of notice }\end{array}\end{array}$ \\
\hline Prior interactions & $\begin{array}{l}\text { How often has your firm done business with the supplier before the purchase } \\
\text { of this product? } 0=\text { never, } 5=\text { many times. }\end{array}$ \\
\hline Expertise & $\begin{array}{l}\text { Does your firm have one or more employees with specific expertise in } \\
\text { the following areas? } 0=\text { no, } 1=\text { yes. } \\
\begin{array}{ll}\text { (a) IT } & \text { (b) Legal }\end{array}\end{array}$ \\
\hline
\end{tabular}

\section{Endnotes}

${ }^{1}$ Contractual incompleteness is a widely used concept in the literature on contracts (Grossman and Hart 1986, Hart and Moore 1990). Contractual completeness can be defined as the ratio of specified clauses over relevant clauses. Bounded rationality afflicts not only contracting parties but also the scholars who study contracts, so it is not feasible to list all relevant clauses for a contract. Therefore, it is impossible to empirically measure contractual (in)completeness. In line with previous research, we focus instead on contractual detail, which is the extent to which clauses are specified in the contract (Poppo and Zenger 2002, Mayer and Argyres 2004, Ryall and Sampson 2009).

${ }^{2}$ On the phone each respondent was asked to mention at least one product in each of the four categories (simple or complex $\mathrm{X}$ software or hardware). A randomized computer procedure picked a single product, ensuring sufficient products from each category in our sample.

${ }^{3}$ Note that alternative coding schemes in which we code "not arranged" as zero and both "oral agreements" and "written agreements" as one, or in which we code "no arrangements" and "oral agreements" as zero and "written agreements" as one do not affect our results.

${ }^{4}$ Because Cronbach's alpha uses variances or Pearson correlations, it is not well defined for ordinal data (on which this scale is based). However, if we assume (a) an underlying continuous variable and (b) that the observed scores for each item are realizations of that variable given certain threshold values $(0,1,2$, in our case), we can still calculate alpha using the standard methods. We used Monte Carlo simulations to assess the sensitivity of alpha to different threshold values for the categories "oral" and "written." In 10,000 runs we fixed the threshold value of "not arranged" at 0 and randomly allowed the threshold value for "oral" to be anywhere between 0 and 2; for "written" it was allowed to be between the threshold value of "oral" and 2. We found that all values of Cronbach's alpha were between 0.82 and 0.84 . We thus conclude that Cronbach's alpha is not sensitive to scaling in our setting and can be appropriately used as an indication of reliability.

${ }^{5}$ The pattern of results when analyzing the 10 legal items separately as dependent variables is similar to the one reported here for the aggregate measure (though significance levels are lower because of increased measurement error).

${ }^{6} \mathrm{We}$ center this variable for constructing interaction terms with IT expertise.

${ }^{7}$ Because we cluster observations from the same buyer to correct for nonindependence, it is technically not possible to include a dummy for this single observation and generate an $F$ statistic. When using clusters, the $F$ statistic is based on the robustly estimated variance error matrix, which is in this case not of sufficient rank to calculate the $F$ statistic.

${ }^{8} \mathrm{We}$ also included separate dummy variables for each of the 15 components instead of our product complexity measure. The results were qualitatively unaffected.

${ }^{9}$ Because legal expertise may be more relevant to legal detail than technical expertise, we also estimated the interaction effects between the linear and squared term of prior interactions and legal expertise on legal detail. The interaction effects were not significant individually, nor were they jointly significant $(p=0.50)$. This is consistent with the weak learning effect in our data for legal detail.

${ }^{10}$ Results for these additional analyses are available on request.

${ }^{11}$ We also considered the possibility that the negative effects for prior interactions are due to "negative" learning-i.e., through repeated interactions exchange partners learn which clauses are irrelevant and subsequently remove those from the contract. However, a theory based on negative and positive learning cannot explain our four main findings (see Table 3 ).

${ }^{12}$ We thank two anonymous reviewers for these useful insights.

${ }^{13}$ Note that technical and legal detail both capture elements of incentive alignment and coordination, and a one-to-one mapping between these is not plausible. 


\section{References}

Akerlof, G. A. 1970. Market for lemons-Quality uncertainty and market mechanism. Quart. J. Econom. 84(3) 488-500.

Anand, B. N., T. Khanna. 2000. Do firms learn to create value: The case of alliances. Strategic Management J. 21(3) 295-315.

Anderson, E., B. Weitz. 1989. Determinants of continuity in conventional industrial channel dyads. Marketing Sci. 8(4) 310-323.

Argote, L. 1999. Organizational Learning: Creating, Retaining, and Transferring Knowledge. Kluwer Academic Publishers, Boston.

Argyres, N. S., K. J. Mayer. 2007. Contract design as a firm capability: An integration of learning and transaction cost perspectives. Acad. Management Rev. 32(4) 1060-1077.

Argyres, N. S., J. Bercovitz, K. J. Mayer. 2007. Complementarity and evolution of contractual provisions: An empirical study of IT services contracts. Organ. Sci. 18(1) 3-19.

Artz, K. W., T. H. Brush. 2000. Asset specificity, uncertainty and relational norms: An examination of coordination costs in collaborative strategic alliances. J. Econom. Behav. Organ. 41(4) 337-362.

Atiyah, P. S. 1989. An Introduction to the Law of Contract. Clarendon Press, Oxford.

Axelrod, R. 1984. The Evolution of Cooperation. Basic Books, New York.

Batenburg, R. S. 1997a. The external management of automation 1995: Codebook of MAT95. ISCORE Paper 58, Utrecht University, Utrecht, The Netherlands.

Batenburg, R. S. 1997b. The external management of automation 1995: Fieldwork, response, and non-response. ISCORE Paper 59, Utrecht University, Utrecht, The Netherlands.

Batenburg, R. S., W. Raub. 1995. The external management of automation 1995. ISCORE datafile, Utrecht University, Utrecht, The Netherlands.

Batenburg, R. S., W. Raub, C. Snijders. 2003. Contacts and contracts: Dyadic embeddedness and the contractual behavior of firms. V. Buskens, W. Raub, C. Snijders, eds. The Governance of Relations in Markets and Organizations, Research in the Sociology of Organizations, Vol. 20. JAI/Elsevier, Oxford, 135-188.

Ben-Shahar, O., J. J. White. 2006. Boilerplate and economic power in auto manufacturing contracts. Michigan Law Rev. 104(5) 953-982.

Boynton, A. C., R. W. Zmud, G. C. Jacobs. 1994. The influence of IT management practice on IT use in large corporations. MIS Quart. 18(3) 299-318.

Bradach, J. L., R. G. Eccles. 1989. Price, authority, and trust-From ideal types to plural forms. Ann. Rev. Sociol. 15 97-118.

Buskens, V. 2002. Social Networks and Trust. Kluwer Academic Publishers, Dordrecht.

Camerer, C., M. Knez. 1996. Coordination, organizational boundaries and fads in business practices. Indust. Corporate Change 5(1) $89-112$.

Cohen, W. M., D. A. Levinthal. 1990. Absorptive capacity: A new perspective on learning and innovation. Admin. Sci. Quart. 35(1) $128-152$.

Corts, K. S., J. Singh. 2004. The effect of repeated interaction on contract choice: Evidence from offshore drilling. J. Law, Econom. Organ. 20(1) 230-260.

Crocker, K. J., K. J. Reynolds. 1993. The efficiency of incomplete contracts: An empirical analysis of air force engine procurement. RAND J. Econom. 24(1) 126-146.
Doz, Y. L. 1996. The evolution of cooperation in strategic alliances: Initial conditions or learning processes? Strategic Management J. 17(7) 55-83.

Dutton, J. M., A. Thomas. 1984. Treating progress functions as a managerial opportunity. Acad. Management Rev. 9(2) 235.

Dyer, J. H. 1996. Specialized supplier networks as a source of competitive advantage: Evidence from the auto industry. Strategic Management J. 17(4) 271-291.

Eisenhardt, K. M. 1989. Agency theory: An assessment and review. Acad. Management Rev. 14(1) 57-74.

Ellis, H. C. 1965. The Transfer of Learning. MacMillan, New York.

Granovetter, M. 1985. Economic action and social structure: The problem of embeddedness. Amer. J. Sociol. 91(3) 481-510.

Grossman, S. J., O. D. Hart. 1986. The costs and benefits of ownership: A theory of vertical and lateral integration. J. Political Econom. 94(4) 691-719.

Gulati, R. 1995. Does familiarity breed trust? The implications of repeated ties for contractual choice in alliances. Acad. Management J. 38(1) 85-112.

Gulati, R., H. Singh. 1998. The architecture of cooperation: Managing coordination costs and appropriation concerns in strategic alliances. Admin. Sci. Quart. 43(4) 781-814.

Gulati, R., P. R. Lawrence, P. Puranam. 2005. Adaptation in vertical relationships: Beyond incentive conflict. Strategic Management J. 26(5) 415-440.

Hamel, G. 1991. Competition for competence and inter-partner learning within international strategic alliances. Strategic Management J. 12(4) 83-103.

Harman, H. H. 1967. Modern Factor Analysis. University of Chicago Press, Chicago.

Hart, O., J. Moore. 1990. Property rights and the nature of the firm. J. Political Econom. 98(6) 1119-1158.

Heath, C., N. Staudenmayer. 2000. Coordination neglect: How lay theories of organizing complicate coordination in organizations. B. M. Staw, R. L. Sutton, eds. Research in Organizational Behavior, Vol. 22. JAI Press, New York, 153-191.

Hennart, J. F. 1993. Explaining the swollen middle-Why most transactions are a mix of market and hierarchy. Organ. Sci. 4(4) 529-547.

Kale, P., J. H. Dyer, H. Singh. 2002. Alliance capability, stock market response, and long term alliance success: The role of the alliance function. Strategic Management J. 23(8) 747-767.

Kale, P., H. Singh, H. Perlmutter. 2000. Learning and protection of proprietary assets in strategic alliances: Building relational capital. Strategic Management J. 21(3) 217-237.

Kalnins, A., K. J. Mayer. 2004. Relationships and hybrid contracts: An analysis of contract choice in information technology. J. Law, Econom. Organ. 20(1) 207-229.

Klein, B., R. G. Crawford, A. A. Alchian. 1978. Vertical integration, appropriable rents, and the competitive contracting process. J. Law Econom. 21(2) 297-326.

Kramer, R. M. 1999. Trust and distrust in organizations: Emerging perspectives, enduring questions. Ann. Rev. Psych. 50(1) 569-598.

Kumar, N., L. W. Stern, J. C. Anderson. 1993. Conducting interorganizational research using key informants. Acad. Management $J$. 36(6) 1633-1651.

Lacity, M. C., L. P. Willcocks, D. F. Feeny. 1995. IT outsourcing: Maximize flexibility and control. Harvard Bus. Rev. 73(3) 84-93. 
Lattin, J. M., J. D. Carrol, P. E. Green. 2003. Analyzing Multivariate Data. Thomson Learning, Pacific Grove, CA.

Llewellyn, K. 1931. What price contract?. An essay in perspective. Yale Law J. 40(5) 704-751.

Luo, Y. 2002. Contract, cooperation, and performance in international joint ventures. Strategic Management J. 23(10) 903-919.

Macaulay, S. 1963. Non-contractual relations in business: A preliminary study. Amer. Sociol. Rev. 28(1) 55-67.

Macneil, I. R. 1978. Contracts: Adjustment of long-term economic relations under classical, neoclassical and relational contract law. Northwestern Univ. Law Rev. 72 854-905.

Mayer, K. J. 2006. Spillovers and governance: An analysis of knowledge and reputational spillovers in information technology. Acad. Management J. 49(1) 69-84.

Mayer, K. J., N. S. Argyres. 2004. Learning to contract: Evidence from the personal computer industry. Organ. Sci. 15(4) 394-410.

Parkhe, A. 1993. Strategic alliance structuring: A game theoretic and transaction cost examination of interfirm. Acad. Management $J$. 36(4) 794-829.

Podsakoff, P. M., D. W. Organ. 1986. Self-reports in organizational research-Problems and prospects. J. Management 12(4) 531-544.

Podsakoff, P. M., S. B. MacKenzie, J.-Y. Lee, N. P. Podsakoff. 2003. Common method biases in behavioral research: A critical review of the literature and recommended remedies. J. Appl. Psych. 88(5) 879-903.

Poppo, L., T. Zenger. 2002. Do formal contracts and relational governance function as substitutes or complements? Strategic Management J. 23(8) 707-725.

Powell, W. W. 1987. Hybrid organizational arrangements-New form or transitional development. Calif. Management Rev. 30(1) 67-87.

Puranam, P., B. S. Vanneste. 2009. Trust and governance: Untangling a tangled web. Acad. Management Rev. 34(1).

Ring, P. S., A. H. Van de Ven. 1992. Structuring cooperative relationships between organizations. Strategic Management J. 13(7) 483-498.

Rooks, G. 2002. Contract en Conflict: Strategisch Management van Inkooptransacties (in Dutch). Thela Thesis, Amsterdam, The Netherlands.
Rooks, G., R. S. Batenburg, W. Raub. 1998. The external management of automation 1998. ISCORE datafile, Utrecht University, Utrecht, The Netherlands.

Ryall, M. D., R. C. Sampson. 2009. Formal contracts in the presence of relational enforcement mechanisms: Evidence from technology development projects. Management Sci. 55(6) 906-925.

Saussier, S. 2000. Transaction costs and contractual incompleteness: The case of Electricite de France. J. Econom. Behav. Organ. 42(2) 189-206.

Simon, H. A. 1957. Models of Man. Wiley, New York.

Skowronski, J. J., D. E. Carlston. 1992. Caught in the act: When impressions based on highly diagnostic behaviours are resistant to contradiction. Eur. J. Soc. Psych. 22(5) 435-452.

Stinchcombe, A. L. 1987. Constructing Social Theories. University of Chicago Press, Chicago.

Stinchcombe, A. L. 1990. Information and Organizations. University of California Press, Berkeley, CA.

Whang, S. 1992. Contracting for software development. Management Sci. 38(3) 307-324.

Williamson, O. E. 1975. Markets and Hierarchies-Analysis and Antitrust Implications. The Free Press, New York.

Williamson, O. E. 1985. The Economic Institutions of Capitalism. The Free Press, New York.

Yelle, L. E. 1979. The learning curve: Historical review and comprehensive survey. Decision Sci. 10(2) 302-328.

Zaheer, A., N. Venkatraman. 1995. Relational governance as an interorganizational strategy: An empirical test of the role of trust in economic exchange. Strategic Management J. 16(5) 373-392.

Zahra, S. A., G. George. 2002. Absorptive capacity: A review, reconceptualization, and extension. Acad. Management Rev. 27(2) 185-203.

Zollo, M., H. Singh. 2004. Deliberate learning in corporate acquisitions: Post-acquisition strategies and integration capability in U.S. bank mergers. Strategic Management J. 25(13) $1233-1256$.

Zollo, M., S. G. Winter. 2002. Deliberate learning and the evolution of dynamic capabilities. Organ. Sci. 13(3) 339-351.

Zollo, M., J. J. Reuer, H. Singh. 2002. Interorganizational routines and performance in strategic alliances. Organ. Sci. 13(6) 701-713. 